\title{
Diversity in insect seed parasite guilds at large geographical scale: the role of host-specificity and spatial distance
}

\begin{tabular}{|r|l|}
\hline Journal: & Journal of Biogeography \\
\hline Manuscript ID & JBI-14-0412.R3 \\
\hline Manuscript Type: & Original Article \\
\hline Date Submitted by the Author: & 01-Dec-2015 \\
\hline Complete List of Authors: & $\begin{array}{l}\text { Bonal, Raul; INDEHESA, University of Extremadura, Forest Research Group } \\
\text { Espelta, Josep; CREAF, Fac. Sciences } \\
\text { Muñoz, Alberto; Faculty of Education, Didáctica de la Ciencias } \\
\text { Experimentales } \\
\text { Ortego, Joaquin; Instituto de Investigación en Recursos Cinegéticos-IREC, } \\
\text { Ecologia } \\
\text { Aparicio, Josep; Instituto de Investigación en Recursos Cinegéticos-IREC, } \\
\text { Ecologia } \\
\text { Gaddis, Keith; University of California-Los Angeles, Ecology and } \\
\text { Evolutionary Biology; UCLA, Institute of the Environment } \\
\text { Sork, Victoria; University of California, Los Angeles, Ecol \& Evol Biology; } \\
\text { UCLA, Institute of the Environment }\end{array}$ \\
\hline Key Words: & $\begin{array}{l}\text { acorn, Quercus spp., seed-feeding insects, spatial autocorrelation, species } \\
\text { turnover, California }\end{array}$ \\
\hline \multicolumn{2}{|c}{} \\
\hline
\end{tabular}


1 Original article

2 Diversity in insect seed parasite guilds at large geographical scale: the role of host-specificity and spatial distance

5 Raúl Bonal ${ }^{1,2,4^{*}}$, Josep M. Espelta ${ }^{3}$, Alberto Muñoz ${ }^{3,5}$, Joaquín Ortego ${ }^{6}$, José Miguel

6 Aparicio $^{4}$, Keith Gaddis ${ }^{7}$ and Victoria L. Sork ${ }^{7}$

7

$8{ }^{1}$ Forest Research Group, INDEHESA, University of Extremadura, Plasencia, Spain

9 2DITEG Research Group, University of Castilla-La Mancha, Toledo, Spain

$10{ }^{3}$ CREAF, Cerdanyola del Vallès, Catalonia, Spain

$11{ }^{4}$ Grupo de Investigación de la Biodiversidad Genética y Cultural, Instituto de

12 Investigación en Recursos Cinegéticos (CSIC-UCLM-JCCM), Ciudad Real, Spain.

13 5epartamento de Didáctica de la Ciencias Experimentales, Facultad de Educación,

14 Universidad Complutense de Madrid, Madrid, Spain

$15{ }^{6}$ Department of Integrative Ecology, Estación Biológica de Doñana (EBD-CSIC),

16 Seville, Spain

$17{ }^{7}$ Department of Ecology and Evolutionary Biology, University of California, Los

18 Angeles, USA

$19 *$ Corresponding author:

20 Raúl Bonal

$21{ }^{1}$ Forest Research Group (GIF), INDEHESA, University of Extremadura, Avda. Virgen

22 del Puerto 2, 10600 Plasencia, Spain

23 e-mail: raulbonal@unex.es

24 Running head: Host-specificity at large geographical scale

25 Word count: 7262 


\section{ABSTRACT}

27 Aim Host specificity within plant-feeding insects constitutes a fascinating example 28 of natural selection that promotes inter-specific niche segregation. If specificity is

29 strong, composition of local plant parasitic insect guilds is largely dependent on

30 the presence and prevalence of the preferred hosts. Alternatively, if it is weak or

31 absent, historic and stochastic demographic processes may drive the structuring of

32 insect communities. We assessed whether the species composition of acorn

33 feeding insects (Curculio spp. guilds) and their genetic variation change

34 geographically according to the local host community.

35 Location An $800 \mathrm{~km}$ transect across California, USA.

36 Methods We used DNA taxonomy to detect potential Curculio cryptic speciation

37 and assessed intra-specific genetic structure among sampling sites. We monitored

38 larval performance on different hosts, by measuring the weight of each larva upon

39 emerging from the acorn. Our phylogenetic and spatial analyses disentangled host-

40 specificity and geographical effects on Curculio community composition and

41 genetic structure.

42 Results DNA taxonomy revealed no specialized cryptic species. Californian

43 Curculio spp. were sister taxa that did not segregate among Quercus species or, at a

44 deeper taxonomic level, between red and white oaks. Curculio species turnover

45 and intra-specific genetic differentiation increased with geographical distance

46 among localities irrespective of local oak species composition. Moreover, larval

47 performance did not differ among oak species or acorn sizes when controlling for

48 the effect of the locality.

49 Main conclusions Historical processes have contributed to the structuring of

50 acorn weevil communities across California. Trophic niche overlapped among 
1

2

3

4

5

6

7

8

9

10

11

12

13

14

15

16

17

18

19

20

21

22

23

24

25

26

27

28

29

30

31

32

33

34

35

36

37

38

39

40

41

42

43

44

45

46

47

48

49

50

51

52

53

54

55

56

57

58

59

60

51 species, indicating that ecologically similar species can co-exist. Acorn crop inter-

52 annual variability and unpredictability in mixed oak forests may have selected

53 against narrow specialization, and facilitated co-existence by means of an inter-

54 specific time partitioning of the resources. Wide scale geographical records of

55 parasitic insects and their host plants are necessary to understand the processes

56 underlying species diversity.

57

58 Keywords acorn, California, Quercus spp., seed-feeding insects, spatial

59 autocorrelation, species turnover.

60

61

62

63

64

65

66

67

68

69

70

71

72

73

74 


\section{INTRODUCTION}

76 The different potential factors underlying species assemblages have been widely

77 debated but still remain a current topic in ecology and, particularly, in plant-insect

78 interactions research. The Competitive Exclusion Principle states that multiple

79 species cannot utilize the same limiting trophic resources indefinitely. Thus

80 selection on each species results from inter-specific specialization that guarantees

81 some portion of the resource is acquired (Hardin 1960). In contrast, the neutral

82 Theory of Biodiversity assumes that competing species are ecologically similar,

83 and predicts that the structure of their communities will depend on historical

84 demographic processes like extinction/migration dynamics (Bell 2001). The Co-

85 existence Theory (Chesson, 2000) supports the Neutral Theory of Biodiversity

86 proposing mechanisms to explain how co-existing competing species can

87 sustainably maintain an overlapping trophic niche.

88 Most previous research aiming to separate the contribution of competition

89 and historical factors on species assemblages has been limited to similar species,

90 usually from a few or single sampling localities (see Skoracka \& Kuczyński, 2012

91 for a review on insect herbivorous guilds), which may neglect historical factors

92 operating at a larger scale. We aim to fill this gap by sampling acorn parasitic

93 insects Curculio spp. captured within multiple host species across a wide

94 geographic scale in the state of California.

95 Insect parasitism on plants is a good example of how intimate species

96 interactions and competition for limited resources can drive specialization (e.g.

97 Cook et al., 2002). Many parasitic insects carry morphological, behavioural, and

98 physicochemical traits adapted to the characteristics of their host plants (i.e.

99 phenology, leaf or seed morphology, physicochemical defences) (Pearse \& Hipp, 
100 2009; Ygel et al., 2011). Trophic specialization drives phylogenetic specificity,

101 which has a variable taxonomic spread: from taxa that feed on plants of the same

102 family or genus to extreme specialists that exploit only one species (reviewed in 103 Barrett \& Heil, 2012).

104 The degree to which specificity is possible within parasitic insects is 105 dependent on the strength of homogenizing and differentiating forces across their 106 range. Specificity may start at the intra-specific level, when local adaptation to 107 different hosts drives divergence between populations of the same parasite species 108 (Thompson, 1999; Drummond et al., 2010). Populations separated in space, with 109 reduced gene flow homogenizing genetic variance, have a greater likelihood of 110 diverging, with taxa splitting into new species that optimize their performance on 111 the preferred hosts to increase their relative fitness (Sword et al., 2005).

112 Nevertheless, differentiation is not always morphologically evident, and may 113 require molecular techniques to discern species (i.e. specialized cryptic species in 114 Murray et al., 2007; review in Barrett \& Heil, 2012). Regional scale records of 115 parasitic insects and their host plants could identify the degree to which host 116 specificity drives regional species diversity, while accounting for the influence of 117 geographic separation and climatic variance that may additionally drive local 118 adaptation.

119 We chose Californian acorn weevils as a case-study because California is a 120 biodiversity hotspot with physical barriers, heterogeneous habitats, and climatic 121 conditions that have dramatically shaped species diversification, distribution, and 122 genetic structure (Calsbeek et al., 2003; Davis et al., 2008). Weevils (Coleoptera: 123 Curculionidae) parasitize oak acorns worldwide (Bonal et al., 2011; Toju \& 124 Fukatsu, 2011; Govindan et al., 2012) and (like most of their endemic host oaks 
125 (Nixon 2002)) are widely distributed across California (Gibson 1969). With such

126 an extensive distribution over a climatically and topographically diverse region,

127 independent geographic effects may have played a significant role in structuring

128 weevil communities. Nevertheless, previous weevil studies have sought only

129 ecological explanations for species structuring. Govindan et al. (2012) reported

130 inter-specific segregation and showed that weevils that fed on acorns of their

131 preferred oak species had a greater survival likelihood. Other authors have

132 hypothesized that inter-specific diversification of weevils has been driven by body

133 size adaptation to the size of the acorns exploited (Hughes \& Vogler, 2004a, Bonal

134 et al. 2011). However, in all cases host records come from taxonomic oriented

135 articles (Gibson 1969), or population-level studies carried out at a small spatial

136 scale examining only a few of the potential host species.

137 Our main objective was to test Curculio spp. host-specificity after

138 accounting for variation in the geographic structure of the parasite species

139 prevalence, genetic differentiation, and performance. Weevils were collected from

140 eight different oak species from the two major sections (Erythrobalanus and

141 Leucobalanus) within the genus Quercus. We sampled the majority of hosts and

142 parasite geographic ranges and performed DNA-based species delimitation of

143 weevils to detect potential host-specialized cryptic taxa. Specifically, i) we studied

144 host species specialization in acorn weevils by assessing whether species turnover

145 and intra-specific genetic differentiation between localities depended on host

146 species similarity or simple spatial proximity; ii) we studied acorn size

147 specialization by comparing the size of the acorns exploited by the different weevil

148 species within the same locality; iii) Finally, we examined weevil weight upon 
149 emerging from an acorn to analyse the potential impact of host-specific ability on

150 weevil performance.

151

152 MATERIAL AND METHODS

153

154 Study area and species

155 From late September to mid October 2010 we sampled at a total of 29 localities

156 widespread over the state of California (North-South and East-West ranges of 805

$157 \mathrm{~km}$ and $531 \mathrm{~km}$, respectively) (Appendix S1; Fig. 1). Each site was georeferenced

158 and we sampled all oak species present, when availability and spatio-temporal

159 variation in crop production (Koenig et al., 1994) permitted. We collected acorns

160 from the most widespread oak species of California, as well as some narrowly

161 distributed endemics, including both red oaks, Erythrobalanus section (Q. agrifolia,

162 Q. kelloggii, Q. wislizenii), and white oaks, Leucobalanus section (Q. lobata, Q.

163 douglasii, Q. engelmanii, Q. berberidifolia, Q. cornellius-mulleri) (Appendix S1).

164 Weevils (Curculio spp. Coleoptera, Curculionidae) are the main pre-

165 dispersal acorn predators and may attack more than $80 \%$ of the crop (Gibson,

166 1969; Bonal et al., 2007; Espelta et al., 2008). Predation occurs by parasitism,

167 when Curculio spp. females oviposit into the acorns, where larvae feed on the

168 cotyledons as they develop. To date, three species of acorn weevils have been

169 recorded in California (C. pardus, C. occidentis and C. aurivestis) with most of their

170 populations located within the study area, spreading marginally to the North and

171 East (Gibson, 1969). To confirm that they do not spread further East, we included

172 in the analyses weevil larvae collected in Utah (37으을 $\left.02^{\prime} 45^{\prime \prime}, 112^{\circ} 43^{\prime} 23^{\prime \prime}\right)$. 
173 Adult weevils were collected by gently shaking the oak branches over a

174 white blanket and larvae were collected from infested acorns. At the laboratory

175 facilities of the University of California Los Angeles (UCLA) adults were identified

176 to the species level following Gibson (1969). Infested acorns were separated into

177 plastic dishes, and kept at $20^{\circ} \mathrm{C}$ to provide identical development conditions to all

178 larvae. After emerging, larvae were weighed and then stored in tubes filled with

$17999 \%$ ethanol for later DNA extraction.

180

181 DNA extraction and sequencing

182 We selected 672 weevils for molecular analyses, balancing the number of

183 individuals between host oak species and localities. We included 14 adults

184 representing the three species of Californian acorn Curculio, the rest $(90 \%$ of the

185 samples) were larvae to be further identified by means of DNA taxonomy (see

186 Pinzon-Navarro et al., 2010 for a similar procedure). DNA was extracted from

187 insect tissue according to the Aljanabi \& Martínez (1997) salt extraction protocol.

188 Individuals were genotyped by amplifying two mitochondrial genes,

189 cytochrome oxidase I (cox1) and cytochrome B (cytb). We used the primers C1-J-

1902183 (Jerry) and L2- N-3014 (Pat) for the first and the universal primers CB1 and

191 CB2 for the second. In addition, we amplified a fragment of the nuclear gene

192 encoding elongation factor $1 \alpha(\mathrm{EF}-1 \alpha)$ using EF1-R and EF1-F primers (see

193 Hughes \& Vogler, 2004b for details on the PCR conditions for the three genes).

194 Sequence chromatograms were assembled and edited using Sequencher 4.6 (Gene

195 Codes Corp., Ann Arbor, MI, USA). The sequences of the three genes (cox1, cytb and

196 EF-1 $\alpha$ ) were trimmed to 711,413 and 581 base pairs respectively to reduce the 
197 proportion of missing data. In the case of the nuclear gene EF- $1 \alpha$ some sequences

198 contained gaps in the intron region.

199

200 Species delimitation and phylogenetic analyses

201 We pooled the cox1 sequences of all individuals to delimit the different species

202 according to the generalized mixed Yule-coalescent (GMYC) model (Pons et al., 203 2006) implemented in R package 'splits', in which we used the 'single threshold' 204 option (Pons et al., 2006). We built a Maximum Likelihood (ML) tree including one 205 copy of each haplotype applying a GTR + I + Gamma substitution model -according 206 to the results of jModelTest 0.1.1 (Posada, 2008). The gall feeding weevil $C$. 207 pyrrhoceras was used as outgroup, as it presents the greatest divergence to the 208 other Curculio species for the three genes analysed (see Hughes \& Vogler, 2004b). 209 The analysis was performed with RAxML 7.0.4 (Stamatakis, 2006) and the 210 resulting tree was made ultrametric under a molecular clock model in 211 PAUP*4.0b10 (Swofford, 2002) with the parameters estimated from the ML 212 search. The GMYC model tracks the tree branching rates and detects the transition 213 from among-species to within-population branching patterns, delimiting 214 'independently evolving' mtDNA clusters. These clusters are called GMYC 215 (putative) species and, if they include sequences from known Linnean species, they 216 may serve to differentiate otherwise indistinguishable specimens like weevil 217 larvae (for which there are no morphological keys) (Pinzon-Navarro et al., 2010). 218 One individual per GMYC group was chosen for a more detailed phylogenetic 219 analysis based on three genes (cox1, cytb and EF-1 $\alpha$ ). Our main objective was to 220 assess the phylogenetic relationships among the Californian weevils to investigate 221 whether host-shifts may be involved in species splitting. To do so we pooled the 
222 Californian sequences with those of another 17 species of American and European

223 Curculio (Hughes \& Vogler, 2004a). The three genes were aligned separately with

224 Clustal W (Thompson et al., 1994). In the case of the nuclear EF-1 $\alpha$ we used the

225 gap opening and gap extension penalties provided by default by Clustal W (15 and

226 6.66, respectively), and visual inspection of the alignment showed that those

227 values were accurate. Next, all genes were concatenated, realigned and our final

228 sequence data file was visually revised to make sure that there were no errors. The

229 gall eating C. pyrrhoceras was the outgroup in all phylogenies (see Hughes \&

230 Vogler, 2004b).

231 We searched for the most reliable tree topology and calculated the support

232 of the tree nodes following two methods (Maximum Likelihood and Bayesian

233 Inference); comparing if the two model-based approaches yielded similar

234 phylogenies. We calculated the best-fit models of nucleotide substitution for each

235 of the three genes according to the Akaike Information Criterion (AIC) using

236 jModelTest 0.1.1 (Posada, 2008). Maximum Likelihood analyses were performed in

237 RAxML 7.2.6 (Stamatakis, 2006) and PHYML 3.0 (Guindon \& Gascuel, 2006). In

238 RAxML three partitions were set (one for each gene) and 10 independent searches

239 conducted. PHYML was additionally used to assess the repeatability of the

240 topology and also because it allows calculating the approximate Likelihood-Ratio

241 Test for branch support, which is a good alternative to nonparametric bootstrap

242 (Guindon \& Gascuel, 2006). Bayesian inference analyses were performed with $\mathrm{Mr}$

243 Bayes 3.2 (Ronquist et al., 2012). We used the same partitions as we used in the

244 Maximum Likelihood tree (RAxML), applying a nucleotide substitution model

245 specific to each gene. Two parallel runs of 2 million generations each were

246 conducted using one cold and two incrementally heated Markov chains $(\Lambda=0.2)$, 
247 sampling every 1,000 steps. We first checked one of the standard convergence

248 diagnostics implemented in MrBayes and then assessed the average standard

249 deviation of the split frequencies to deduce that the Markov chain had reached

250 stationarity. After 500,000 generations, the average standard deviation of the split

251 frequencies stabilized in values close to zero (0.001). Hence, phylogenetic trees

252 were summarized using the all-compatible consensus command with $25 \%$ burn-in.

253

254 Intra-specific genetic structure

255 We analysed inter-population genetic differentiation in those species (C. pardus

256 and C. occidentis) that had a sufficient number of specimens per sampling locality

257 (see below the choice criteria). We performed analyses of the molecular variance

258 (AMOVAs) using ARLEQUIN software (Excoffier et al., 2005) and also tested

259 whether there was any geographic pattern in the population genetic structure

260 using SAMOVA version 1.0 (Dupanloup et al., 2002). This method identifies the

261 optimal grouping option (K) that maximises the among-group component (FCT) of

262 the overall genetic variance. We defined the number of populations $(\mathrm{K})$ and ran

263100 simulated annealing processes. We simulated different numbers of

264 populations, ranging from $K=2$ to $K=19$, to determine the best population

265 clustering option.

266

267 Curculio intra-specific genetic dissimilarities among hosts and localities

268 We performed intra-specific analyses on C. pardus and C. occidentis (C. aurivestis

269 samples did not reach a sufficient number per site). We included only those

270 localities in which there were sequences for at least 4 individuals per species (see

271 Papadopoulou et al., 2011 for a similar approach). Above this threshold we 
272 confirmed that there was no effect of sample size on either genetic (C. pardus: $r=$

$2730.31, p=0.17, n=20 ;$ C. occidentis: $r=0.09, p=0.68, n=19$ ) or nucleotide diversity

274 (C. pardus: $r=0.21, p=0.36, n=20 ;$ C. occidentis: $r=0.001, p=0.99, n=19$ ). We

275 used Arlequin 3.1 (Excoffier et al., 2005) to compute genetic dissimilarities by

276 assessing the raw average number of differences among populations (Nei's D) in

277 the mitochondrial gene cox1. DNA microsatellites (nuclear DNA) have yet to be

278 developed for these species and, although they can provide finer resolution in

279 genetic analysis, in other Curculio spp. mitochondrial markers have detected

280 population structure at scales of just a few kilometres and distinguished host-

281 adapted morphotypes (Toju \& Sota, 2006; Toju et al., 2011). Host-oak

282 dissimilarities were calculated using Bray-Curtis index on the number of Curculio

283 individuals sampled on each oak species and its correlation with intra-specific

284 genetic dissimilarities was analysed controlling for the effect of the Euclidean

285 geographical distance between localities using partial Mantel tests as implemented

286 in the R package 'ecodist’ (Goslee \& Urban, 2007).

287

288 Local oak community composition and Curculio species turnover among sites

289 Due to variable insect availability it was not always possible to balance weevil

290 sample size across sites and Quercus species, hence we included those 25 localities

291 with 9 or more individuals (Appendix S1). Above that number we found no

292 significant effect of sample size on either the number of species (Spearman

293 correlation: $r=0.34, p=0.14, n=25$ ) or species $\alpha$-diversity (Spearman correlation:

$294 r=0.10, p=0.60, n=25$ ) collected at a site. Further, in 16 localities in which

295 sample size was greater than 18, we calculated the mean rarified number of

296 species standardized first for 9 and then for 18 individuals, and found no 
297 significant differences between the two estimates (ANOVA: $F_{1,30}=0.57 ; p=0.45$ ).

298 Species diversity and richness measures were calculated using the R package

299 'vegan' (Oksanen et al., 2012). Statistical analyses were performed using R (R

300 Development Core Team, 2012).

301 We examined the influence of host-oak communities on weevil species

302 compositional dissimilarity. Pairwise Curculio species turnover among localities

303 was assessed with the Bray-Curtis index. This index is calculated using species

304 presence/absence and relative abundance, making it less affected by low species

305 numbers. We measured the correlation between Curculio spp. and host-oak

306 similarities with a partial Mantel test (10000 permutations) using the Euclidean

307 geographical distance among localities as a control for potential spatial auto-

308 correlation effects (Koenig, 1999). We ran this analysis using the R package

309 'ecodist' (Goslee \& Urban, 2007).

310

311 Curculio inter-specific segregation according to host size

312 We assessed whether acorns were partitioned by size among the larvae of $C$.

313 pardus and C. occidentis. Curculio aurivestis was not included due to low sample

314 sizes. The raw weight of infested acorns is an unreliable estimate of acorn size, as

315 weight varies with the amount of cotyledon eaten by the larvae inside. Instead, we

316 used linear dimensions of each acorn (length and width to the nearest $0.01 \mathrm{~mm}$ ) to

317 estimate acorn mass using the formula detailed in Bonal et al. (2007). In those

318 localities where both weevil species co-existed and at least three larvae of each

319 species were collected, we compared the size of the acorns exploited by each with

320 a paired Student's t-test. As body size affects the size of the acorns used (Bonal et

321 al., 2011), we also compared C. pardus and C. occidentis larval weight with a paired 
322 Student's t-test.

323

324 Curculio performance according to host species identity and host seed size

325 We estimated Curculio performance by recording the larval weight (to the nearest

$3260.1 \mathrm{mg}$ ) when they emerged from infested acorns. Larval weight is a key life-

327 history trait in most insects and a good fitness proxy. Within Curculio weevils

328 larval weight determines to a large extent survival likelihood and potential

329 fecundity (Desouhant et al., 2000; Bonal et al., 2012). We dried all the infested

330 acorns at $80^{\circ} \mathrm{C}$ for 48 hours before opening them one month after the last larva

331 had emerged. We found that the cotyledons were never depleted within our

332 samples, so any difference in larval weight would be the due to the nutritional

333 quality of the acorn rather than to food constraints.

334 We used an ANCOVA to test the effect of the host oak species (fixed factor)

335 and acorn mass (covariate) on larval weight (dependent variable). Sampling

336 locality was included as a random effect because insect body size has been shown

337 to be susceptible to changes at geographic scale due to environmental differences

338 among localities (Mousseau \& Roff, 1989). We ran this analysis first examining all

339 weevils, and then used just those collected on the most commonly sampled oak

340 species (Q. lobata) to remove any potential confounding effect of host species

341 identity. Statistical analyses were performed with Statistica 7.0 (Statsoft, Inc Tulsa,

342 OK, USA).

343

344

345

346

347 


\section{RESULTS}

349

350

DNA-based weevil species delimitation and phylogenetic analyses

351 A total of 540 cox 1 sequences from adult weevils and larvae had the necessary

352 length to be included in the analyses (of these 529 were collected in California and

35311 in Utah). We did not get sequences for the remaining 132 individuals (20\%),

354 either due to PCR issues, or because the sequences obtained were not long enough.

355 These 540 sequences were collapsed into 138 different haplotypes that were used

356 to build the ultrametric clock-constrained Maximum Likelihood phylogeny

357 subjected to the GMYC analysis, which grouped the sequences in 4 clusters

358 corresponding to distinct putative species. Three of these clusters included

359 sequences obtained from both adults and larvae collected in California. All clusters

360 corresponded to just one previously-named species (C. pardus, C. aurivestis or $C$.

361 occidentis). All adult species assignments based on morphological characters

362 matched the species assignment based on the GMYC cluster, confirming the

363 reliability of our genetic methods and ability to accurately determine all larvae to

364 the species level. The fourth cluster corresponded to the weevil larvae collected in

365 Utah and could not be identified because their sequences did not group with any

366 acorn Curculio species available in GenBank; they were named GMYC 51 (Fig. 2).

367 The three phylogenies built on the combined three genes set (mitochondrial

368 cox1 and citb; nuclear EF-1 $\alpha$ ) retrieved the same topology (Fig. 2). The tree shows

369 a clear division between North American and European species, which form

370 different clades with a very strong branch support. The Californian acorn weevil

371 species constitute an independent subclade within the American clade (Fig. 2).

372 There is strong support for a sister species relationship between C. aurivestis and 
373 C. occidentis, and comparatively low support for a monophyletic clade containing $C$.

374 pardus, C. aurivestis and C. occidentis, indicating that the relationship of C. pardus to

375 the other two species is less certain.

376

377 Host-specificity and species turnover

378 The phylogenetic tree shows that host shifts between oak species or sections (red

379 and white oaks) were not involved in the speciation of the Californian acorn

380 Curculio spp. (Fig. 2). Curculio pardus and C. occidentis were present on all Quercus

381 spp. sampled with the exception of $C$. occidentis on $Q$. cornellius-mulleri. The scarce

382 C. aurivestis was not found on Q. wislizenii, Q. kellogii and Q. berberidifolia.

383 Species distribution patterns were defined by geographic restriction and

384 not host tree assembly (Fig. 1). The Mantel test showed that geographically more

385 distant populations harboured more dissimilar Curculio spp. communities $(r=$

$3860.14, p=0.03$ ), but host oak similarity among localities was non-significant when

387 examined at the species $(r=0.02, p=0.32)$, and at the section level, comparing red

388 and white oaks $(r=0.09, p=0.11)$ after controlling for the effect of pairwise

389 geographical distances among localities (Fig. 1).

390

391 Intra-specific genetic structure

392 Curculio pardus and C. occidentis showed contrasting patterns of genetic structure.

393 The results of the AMOVA for C. pardus indicate a significant genetic differentiation

394 among populations explaining $59 \%$ of the molecular variance ( $\mathrm{df}=19, p<0.0001)$.

395 The geographical pattern retrieved by the SAMOVA showed three clusters (Fig. 3),

396 explaining a $67 \%$ of the molecular variance ( $\mathrm{df}=2, p<0.0001)$. One cluster was

397 distributed around the Central Valley from Monterrey Bay and Central Sierra 
398 Nevada northwards. The second was found on both sides of the southern half of 399 the Valley. The third cluster grouped populations located south of the Transverse 400 Ranges. Inter-population genetic differentiation for C. occidentis was lower than for 401 C. pardus, accounting for $19 \%$ of the molecular variance, but still significant (df $402=19, p<0.0001)$. The geographical pattern retrieved by the SAMOVA for $C$. 403 occidentis identified just two clusters, explaining $30 \%$ of the molecular variance (df $404=1, p<0.001$ ). One of these clusters included all the populations around the 405 Central Valley and the other comprised a single population south of the Transverse 406 Ranges (Fig. 3).

407

408 Host-specificity and genetic similarity

409 We found no evidence of intra-specific genetic differentiation among weevils 410 according to host oak species or sections. In the case of $C$. pardus, Mantel tests 411 showed that genetic dissimilarity among sites was strongly correlated with 412 geographic distance $(r=0.46, p<0.001)$. However, differences in local host tree 413 community composition had no effect on weevil intra-specific genetic 414 differentiation either at the oak species $(r=-0.07, p=0.78)$ or the taxonomic 415 section (red/white oaks) levels $(r=0.01, p=0.41)$. Like $C$. pardus, similarity in host 416 trees community composition among sites had no effect on $C$. occidentis genetic 417 similarity (oak species: $r=-0.05, p=0.63$; red/white oak sections: $r=-0.16, p=$ 418 0.11). However, unlike C. pardus, pairwise geographical distance did not 419 significantly explain genetic dissimilarity in $C$. occidentis $(r=0.15, p=0.11)$. 420

421 Curculio inter-specific segregation according to acorn size 
422 Both the size of infested acorns and the weight of the larvae of $C$. pardus and $C$.

423 occidentis did not differ significantly. Where both weevil species co-existed, the

424 mean size of the acorns infested by $C$. pardus and $C$. occidentis were $3.66 \pm 0.30$ and

$4253.81 \pm 0.33$ respectively (paired Student's t-test: $t=0.65, \mathrm{df}=14, p=0.52$ ). Larval

426 weight also did not differ between the two weevil species (paired Student's $t$-test: $t$

$427=-1.81, \mathrm{df}=9, p=0.11)$.

428

429 Curculio performance in the different host species

430 Larvae performance did not change significantly among host oaks, but did differ

431 among localities. The weights (mean \pm SE) of $C$. pardus larvae collected on $Q$.

432 agrifolia, Q. berberidifolia, Q. douglasii and $Q$. lobata were $44 \pm 4,43 \pm 3,46 \pm 1$ and

$43349 \pm 1$ milligrams, respectively. These differences among oak species were not

434 significant $\left(F_{3,91}=0.28, p=0.59\right)$, and the covariate acorn size had no significant

435 effect either $\left(F_{1,91}=0.36, p=0.54\right)$. Locality (included as a random effect) was the

436 only significant explanatory variable $\left(F_{12,91}=2.07, p=0.02\right)$. We found similar

437 results for $C$. occidentis. Larval weights (mean \pm SE) were $35 \pm 1,37 \pm 2,39 \pm 2,41 \pm 1$

438 and $42 \pm 2$ milligrams within Q. agrifolia, Q. berberidifolia, Q. douglasii, Q. lobata, and

439 Q. wislizenii, respectively. As we saw in C. pardus, neither the fixed factor (oak

440 species $)\left(F_{4,135}=2.06, p=0.27\right)$ nor the covariate (acorn mass) $\left(F_{1,135}=0.73, p=\right.$

441 0.39) significantly explained $C$. occidentis larval weight. In contrast to $C$. pardus,

442 locality (random effect) had no effect on larval weight for $C$. occidentis $\left(F_{17,135}=\right.$

$4433.98, p=0.28)$.

444 When larvae feeding on the same oak species (Q. lobata) were compared, 445 there was a significant effect of the locality on larval weight of both $C$. pardus $\left(F_{7,55}\right.$ $446=2.56, p=0.02 ;$ Fig. $4 \mathrm{a})$ and $C$. occidentis $\left(F_{12,71}=3.87, p<0.0001 ;\right.$ Fig. $\left.4 \mathrm{~b}\right)$, even 
447 after controlling for acorn mass, which had no significant effect $\left(F_{1,55}=2.16, p=\right.$

448 0.14; Fig. 4 a for $C$. pardus, and $F_{1,71}=1.49, p=0.42$; Fig. $4 \mathrm{~b}$ for $C$. occidentis).

449

450

\section{DISCUSSION}

451 Our results show a strong trophic niche overlap among Californian acorn weevils.

452 Additionally, larval performance did not differ between host species, supporting a

453 lack of specialization. Species turnover and intra-specific genetic structure of

454 weevils were spatially arranged independently of host oak species assembly,

455 which suggests that historical processes have contributed to the assemblage of

456 acorn weevil communities across California.

457 Californian Curculio form a monophyletic subclade within the North

458 American clade, probably due to historic isolation in a region with a high number

459 endemic plants and animals (Nixon, 2002; Calsbeek et al., 2003). All species we

460 examined in California were observed feeding on both red and white oaks,

461 indicating that strict host-specificity has not triggered speciation in Californian

462 weevils. Moreover, DNA taxonomy ruled out any cryptic speciation and trophic

463 niche segregation among morphologically similar species. At the Quercus species

464 level, the absence of $C$. occidentis within the samples collected from Q. cornellius-

465 mulleri is probably a matter of sample size, as that oak was present in just one site

466 in which few weevils were collected. Similarly, although C. aurivestis was not found

467 at any site with Q. wislizenii, Q. kellogii and Q. berberidifolia present, it was the least

468 common weevil species collected. This may be a question of range limitation rather

469 than of host-specificity, as when the oak species on which C. aurivestis had been

470 collected at other locations shared the same location with these three oaks, this

471 weevil species was absent. 
472 The spatial arrangement of genetic variance across weevil populations

473 suggests an important role of the complex geographic history of California in

474 structuring weevil communities. The populations south of the Transverse Range

475 for both Curculio species differed significantly from the rest of the distribution to

476 the north (Fig. 3), a pattern frequently found in many Californian plant and animal

477 taxa (Calsbeek et al., 2003; Davis et al., 2008; Vandergast et al., 2008). We

478 identified a genetic split between the northern and southern halves of the Central

479 Valley within C. pardus, with boundaries at Monterrey Bay and Sierra Nevada.

480 Areas with greater genetic connectivity among Sierra and coastal populations of $C$.

481 pardus are the same valley corridors identified by the host oak Q. lobata (Gugger et

482 al., 2013). Historically, the populations of many Californian species were split by

483 the Sierra Nevada uplifts and the flooding of extensive areas of the San Joaquin

484 Valley via the inland waterway from Monterrey Bay (ca. 5 to 2.5 million years ago)

485 (e.g. Kuchta et al., 2009; Satler et al., 2011; Gugger et al., 2013). Nevertheless, the

486 barrier effect of the Transverse Range predates this division, creating a stronger

487 separation for numerous species (Calsbeek et al., 2003; Vandergast et al., 2008). If

488 C. occidentis spread northwards later than C. pardus (when those barriers had

489 already disappeared) less differentiation among populations of the former species

490 north of these mountains would have established. Alternatively, previous studies

491 have demonstrated that the dispersal abilities can differ among Curculio species

492 (Govindan et al., 2012; Pélisson et al., 2013). If the dispersal abilities of $C$.

493 occidentis are higher than those of $C$. pardus, the above mentioned past

494 geographical barrier might have had less effect in the former.

495 Our extensive sampling showed that larval weight, which is a strong proxy

496 of fitness (Desouhant et al., 2000, Bonal et al., 2012), differed among localities but 
497 not among host oaks. As all larvae were grown experimentally in the same

498 environment we could rule out direct local effects on larval growth. Hence,

499 differences in larval weight among localities are more likely the result of random

500 drift or local adaptation (Mousseau \& Roff, 1989). These effects were more

501 pronounced in C. pardus, which differed significantly among localities and when

502 considering only the localities where Q. lobata was present. Given that C. pardus

503 also exhibited a stronger genetic association with geography, it is possible that this

504 difference may signal underlying genetic differences and local adaptation.

505 The lack of differences in larval performance between host oaks supports

506 the absence of specificity, as specialists achieve a higher fitness on their preferred

507 hosts (Sword et al., 2005). Variation in acorn tannin content among oak species

508 (Pyare et al., 1993) might have promoted specialization. Recent studies have found

509 mechanisms (endosymbiotic bacteria) in some Curculio spp. that facilitate host

510 specific digestive ability (Toju \& Fukatsu, 2011; Merville et al., 2013).

511 Nevertheless, our results do not suggest this type of adaptation in Californian

512 acorn weevils, as larval performance did not differ among host oaks. We did not

513 find inter-specific segregation according to acorn size either. As body size is the

514 common determinant of acorn size specialization (Bonal et al., 2011), and it did not

515 differ significantly among Curculio spp., it does not seem likely that any size

516 segregation is occurring.

517 The lack of trophic niche partitioning within these acorn weevils is puzzling,

518 but may be driven by stochastic resource availability. Similar patterns in other

519 herbivorous arthropods have been often attributed to nutritional advantages of a

520 generalist diet or the lower vulnerability to parasitoids (Bernays \& Graham, 1988;

521 McCormick et al., 2012). Our findings in acorn weevils may be the product of an 
522 unpredictable and not always synchronized acorn crop among co-occurring oak

523 species (Koenig et al., 1994; Espelta et al., 2008). When resource availability is

524 unpredictable, a generalist weevil species would be more likely to find a suitable

525 acorn to oviposit each year. On the contrary, a narrow specialist strategy would

526 only persist if the increased fitness on the preferred host compensates the risks of

527 not reproducing when that host is unavailable. For instance, leaf chewers and

528 miners exploit a food source (i.e. leafs) that is predictably abundant each year, thus

529 most species are frequently specialized on specific oak species or taxonomic

530 sections (Cook et al., 2002; Pearse \& Hipp, 2009).

531 The absence of segregation among host species and acorn sizes draws a

532 picture of weevil communities with a strong inter-specific trophic niche overlap.

533 The Co-existence Theory (Chesson, 2000) proposes that storage effects stabilize

534 population levels to prevent complete competitive dominance when species are

535 affected differently by environmental variation in space and/or time (Chesson,

536 2000). This mechanism fits well with Curculio spp. life-histories, as they feed on a

537 resource (acorns) available for a limited annual time period with an unpredictable

538 abundance due to oak mast-seeding (Koenig et al., 1994; Espelta et al., 2008). In

539 turn, adult weevils emerge and reproduce after an underground diapause that may

540 last between 1 to 4 years depending on the species. This inter-specific time

541 partitioning across years means that unpredictable large crops do not always

542 benefit the same species (Venner et al., 2011), and allows one taxa to get largely

543 out competed for resources one year, yet still maintain a stable population. It is

544 possible that resource partitioning across years may account for our results,

545 however, future studies analysing long term weevil abundance are necessary in

546 order to verify such a pattern. 
547 Inter-specific differences in reproductive phenology lead in some cases to

548 an additional within year time partitioning that favours co-existence (Pélisson et

$549 a l ., 2013)$. In years of low acorn production, early reproducing species occupy most

550 available acorns. On the contrary, late reproducing ones are benefited when the

551 number of acorns is not limiting. In those years, their larvae grow within larger full

552 sized acorns and are more likely to finish their development successfully

553 compared to early reproducing species (Bonal et al., 2011, Venner et al., 2011).

554 When there is temporal segregation within the same year, the size of the infested

555 acorns differs among weevil species (Bonal et al., 2011), and this is not what we

556 found for Californian acorn weevils. However, as we do not have detailed

557 information about their emergence timing, we cannot rule out that their co-

558 existence might also be stabilized by within year time partitioning.

559 In conclusion, our results reveal no trophic specialisation within Curculio

560 species indicating the potential importance of historical processes (e.g. dispersal,

561 extinction/migration dynamics) in the structuring of acorn weevil communities

562 across California and show that ecologically similar seed predators can co-exist

563 exploiting the same host species. The marked inter-annual variability and

564 unpredictability of acorn crops in mixed oak forests may have selected against

565 narrow specialization, and facilitated co-existence by means of an inter-specific

566 time partitioning of the resources. The present study shows the usefulness of wide

567 geographical records of parasitic insects and their host plants to set light on the

568 processes underlying species diversity.

570

571 
572

\section{ACKNOWLEDGEMENTS}

574

575 This work was financed by the projects: CONSOLIDER-MONTES CSD2008-00040

576 MICINN, PII1C09-0256-9052 JCCM and ESF, AGL2014-54739-R, PPII-2014-01-

577 PJCCM ESF and CGL2008-00095 /BOS (MICINN). A.M. was funded by a Juan de la

578 Cierva contract and RB by a contract of the Atracción de Talento Investigador

579 Programme (Gobierno de Extremadura TA13032). J.O. was funded by Severo

580 Ochoa (SEV-2012-0262) and Ramón y Cajal (RYC-2013-12501) research

581 fellowships. Marisa Hernández helped with the lab work. Two anonymous

582 reviewers provided helpful comments on earlier drafts of the manuscript.

583

584 REFERENCES

585 Aljanabi, S.M. \& Martínez, I. (1997) Universal and rapid salt-extraction of high

586 quality genomic DNA for PCR-based techniques. Nucleic Acids Research, 25, 4692-

5874693.

588 Barrett, L. G. \& Heil, M. (2012) Unifying concepts and mechanisms in the specificity

589 of plant-enemy interactions. Trends in Plant Science, 17, 282-292.

590 Bell, G. (2001) Neutral Macroecology. Science, 293, 2413-2418.

591 Bernays, E. \& Graham, M. (1988) On the evolution of host specificity in

592 phytophagous arthropods. Ecology, 69, 886-892. 
593 Bonal, R., Muñoz, A. \& Díaz, M. (2007) Satiation of predispersal seed predators: the

594 importance of considering both plant and seed levels. Evolutionary Ecology, 21, $595 \quad 367-380$.

596 Bonal, R., Espelta, J. M. \& Vogler, A. P. (2011) Complex selection on life-history 597 traits and the maintenance of variation in exaggerated rostrum length in acorn 598 weevils. Oecologia, 167, 1053-1061.

599 Bonal, R., Hernández, M., Ortego, J., Muñoz, A. \& Espelta, J. M. (2012) Positive 600 cascade effects of forest fragmentation on acorn weevils mediated by seed size 601 enlargement. Insect Conservation and Diversity, 5, 381-388.

602 Calsbeek, R., Thompson, J. N. \& Richardson, J. E. (2003) Patterns of molecular 603 evolution and diversification in a biodiversity hotspot: the California Floristic 604 Province. Molecular Ecology, 12, 1021-1029.

605 Cook, J. M., Rokas, A., Pagel, M. \& Stone, G. N. (2002) Evolutionary shifts between 606 host oak sections and host-plant organs in Andricus gallwasps. Evolution, 56, $607 \quad 1821-1830$.

608 Davis, E. B., Koo, M. S., Conroy, C., Patton, J. L. \& Moritz, C. (2008) The California 609 Hotspots Project: identifying regions of rapid diversification of mammals. 610 Molecular Ecology, 17, 120-138

611 Desouhant E., Debouzie D., Ploye H. \& Menu F. (2000) Clutch size manipulations in 612 the chestnut weevil, Curculio elephas: fitness of oviposition strategies. Oecologia, $613122,493-499$. 
614 Drummond, C. S., Xue, H. J., Yoder, J. B. \& Pellmyr, O. (2010) Host-associated

615 divergence and incipient speciation in the yucca moth Prodoxus coloradensis

616 (Lepidoptera: Prodoxidae) on three species of host plants. Heredity, 105: 183-196.

617 Dupanloup, S., Schneider \& Excoffier, L. (2002) A simulated annealing approach to 618 define the genetic structure of populations. Molecular Ecology, 11, 2571-2581.

619 Espelta J. M., Cortés P., Mollowny-Horas, R., Sánchez-Humanes, B. \& Retana, J.

620 (2008) Masting mediated by summer drought reduces acorn predation in

621 mediterranean oak forests. Ecology, 89, 805-817.

622 Excoffier, L., Laval G. \& Schneider, S. (2005) Arlequin ver. 3.0: An integrated

623 software package for population genetics data analysis. Evolutionary

624 Bioinformatics Online, 1, 47- 50.

625 Gibson, L. P. (1969) Monograph of the genus Curculio in the New World

626 (Coleoptera: Curculionidae). Part I. United States and Canada. Miscellaneous

627 Publications of the Entomological Society of America, 6, 240-285.

628 Goslee, S. C. \& Urban, D. L. (2007) The "ecodist" package for dissimilarity-based 629 analysis of ecological data. Journal of Statistical Software, 22, 1-19.

630 Govindan, B. N., Kery, M. \& Swihart, R. K. (2012) Host selection and responses to

631 forest fragmentation in acorn weevils: inferences from dynamic occupancy models.

632 Oikos, 121, 623-633.

633 Gugger, P. F., Ikegami, M. \& Sork, V. L. (2013) Influence of late Quaternary climate

634 change on present patterns of genetic variation in valley oak, Quercus lobata Née.

635 Molecular Ecology, 22, 3598-3612. 
636 Guindon, S. \& Gascuel, O. (2006) A simple, fast and accurate algorithm to estimate

637 large phylogenies by maximum likelihood. Systematic Biology, 52, 696-704.

638 Hardin, G. (1960) The Competitive Exclusion Principle. Science, 131, 1292-1297.

639 Hughes, J. \& Vogler, A. P. (2004a). Ecomorphological adaptation of acorn weevils to 640 their oviposition site. Evolution, 58, 1971-1983.

641 Hughes, J., \& Vogler, A. P. (2004b) The phylogeny of acorn weevils (genus Curculio)

642 from mitochondrial and nuclear DNA sequences: the problem of incomplete data.

643 Molecular Phylogenetics and Evolution, 32, 601-615.

644 Koenig, W. H., Mumme, R. L.. Carmen, W. J. \& Stanback, M. T. (1994) Acorn

645 production by oaks in central coastal California: Variation within and among years.

646 Ecology, 75, 99-109.

647 Koenig, W. (1999) Spatial autocorrelation of ecological phenomena. Trends in 648 Ecology and Evolution, 14, 22-26.

649 Kuchta, S. R., Parks, D. S., Mueller, R. L. \& Wake, D. B. (2009) Closing the ring:

650 historical biogeography of the salamander ring species Ensatina eschscholtzii.

651 Journal of Biogeography, 36, 982-995.

652 McCormick, A.C., Unsicker, S.B. \& Gershenzon, J. (2012) The specificity of

653 herbivore-induced plant volatiles in attracting herbivore enemies. Trends in Plant

654 Science, 17, 303-310. 
655 Merville, A., Venner, S., Henri, H., Vallier, A., Menu, F., Vavre, F., Heddi, A. \& Bel-

656 Venner, M.C. (2013) Endosymbiont diversity among sibling weevil species

657 competing for the same resource. BMC Evolutionary Biology, 13, 28.

658 Mousseau, T. A. \& Roff, D. A. (1989) Adaptation to seasonality in a cricket -

659 Patterns of phenotypic and genotypic variation in body size and diapause

660 expression along a cline in season length. Evolution, 43, 1483-1496.

661 Murray, T. E., Fitzpatrick, Ú., Brown, M. J. \& Paxton, R. J. (2007) Cryptic species

662 diversity in a widespread bumble bee complex revealed using mitochondrial DNA

663 RFLPs. Conservation Genetics, 9, 653-666.

664 Nixon, K. C. (2002) The Oak (Quercus) Biodiversity of California and Adjacent

665 Regions 1. - In: USDA Forest Service (eds.) General Technical Report PSW-GTR-

666 184. pp. 3-20.

667 Oksanen, J., Blanchet, F. G., Kindt, R., Legendre, P., Minchin, P. R., O'Hara, R. B.,

668 Simpson, G. L., Solymos, P., Henry, M., Stevens, H. \& Wagner, H. (2011) vegan:

669 Community Ecology Package. R package version 2.0-2. http://CRAN.R-

670 project.org/package=vegan

671 Papadopoulou, A., Anastasiou, I., Spagopoulou, F., Stalimerou, M., Terzopoulou, S.,

672 Legakis, A. \& Vogler, A. P. (2011) Testing the species--genetic diversity correlation

673 in the Aegean archipelago: toward a haplotype-based macroecology? American

$674 \quad$ Naturalist, 178, 241-55. 
675 Pearse, I. S. \& Hipp, A. L. (2009) Phylogenetic and trait similarity to a native species

676 predict herbivory on non-native oaks. Proceedings National Academy of Sciences U.

677 S. A., 106, 18097-18102.

678 Pélisson, P. F., Bernstein, C., François, D., Menu, F. \& Venner, S. (2013) Dispersal

679 and dormancy strategies among insect species competing for a pulsed resource.

680 Ecological Entomology, 38, 470-477.

681 Pélisson, P. F., Bel-Venner, M. C., Giron, D., Menu, F. \& Venner, S. (2013). From

682 Income to Capital Breeding: When Diversified Strategies Sustain Species

683 Coexistence. PLoS ONE, 8, e76086.

684 Pinzon-Navarro, S., Barrios, H., Murria, C., Lyal, C. H. C. \& Vogler, A. P. (2010) DNA-

685 based taxonomy of larval stages reveals huge unknown species diversity in

686 neotropical seed weevils (genus Conotrachelus): relevance to evolutionary ecology.

687 Molecular Phylogenetics and Evolution, 56, 281-293.

688 Pons, J., Barraclough, T., Gomez-Zurita, J., Cardoso, A., Duran, D., Hazell, S., Kamoun,

689 S., Sumlim, W. D. \& Vogler, A. P. (2006) Sequence-based species delimitation for the

690 DNA taxonomy of undescribed insects. Systematic Biology, 55, 595-609.

691 Posada, D. (2008) jModelTest: Phylogenetic Model Averaging. Molecular Biology

692 and Evolution, 25, 1253-1256.

693 Pyare, S., Kent, J.A., Noxon, D.L. \& Murphy, M.T. (1993) Acorn preference and

694 habitat use in eastern chipmunks. American Midland Naturalist, 130, 173-183.

695 Ronquist, F., Teslenko, M., van der Mark, P., Ayres, D.L., Darling, A., Höhna, S.,

696 Larget, B., Liu, L., Suchard M.A. \& Huelsenbeck, J.P. (2012) MrBayes 3.2: Efficient 
697 Bayesian Phylogenetic Inference and Model Choice Across a Large Model Space.

698 Systematic Biology, 61, 539-542.

699 Satler, J.D., Starrett, J., Hayashi, C.Y. \& Hedin, M. (2011) Inferring species trees from

700 gene trees in a radiation of California trapdoor spiders (Araneae, Antrodiaetidae,

701 Aliatypus). PLoS ONE, 6, e25355.

702 Skoracka, A. \& Kuczyński, L. (2012) Measuring the host specificity of plant-feeding

703 mites based on field data - a case study of the Aceria species. Biologia, 67, 546-

704560.

705 Stamatakis, A. (2006) RAxML-VI-HPC: maximum likelihood-based phylogenetic

706 analyses with thousands of taxa and mixed models. Bioinformatics, 22, 2688-2690.

707 Swofford, D.L. (2002) PAUP: Phylogenetic Analysis using Parsimony. Version 4.0b.

708 Sinauer Associates, Sunderland, MA.

709 Sword, G.A., Joern, A. \& Senior, L.B. (2005) Host plant-associated genetic

710 differentiation in the snakeweed grasshopper, Hesperotettix viridis (Orthoptera:

711 Acrididae). Molecular Ecology, 14, 2197-2205.

712 Thompson, J. D., Higgins, D. G. \& Gibson, T. J. (1994) CLUSTAL W: improving the

713 sensitivity of progressive multiple sequence alignment through sequence

714 weighting, position specific gap penalties and weight matrix choice. Nucleic Acids

715 Research, 22, 4673-4680.

716 Thompson, J. N. (1999) Specific hypotheses on the geographic mosaic of

717 coevolution. American Naturalist, 153, S1-S14. 
718 Toju, H. \& Sota, T. (2006) Phylogeography and the geographic cline in the

719 armament of a seed-predatory weevil: effects of historical events vs. natural

720 selection from the host plant. Molecular Ecology, 15, 4161-4173.

721 Toju, H., Ueno, S., Taniguchi, F. \& Sota, T. (2011) Metapopulation structure of a

722 seed-predator weevil and its host plant in arms race coevolution. Evolution, 65,

723 1707-1722.

724 Toju, H. \& Fukatsu, T. (2011) Diversity and infection prevalence of endosymbionts

725 in natural populations of the chestnut weevil: relevance of local climate and host

726 plants. Molecular Ecology, 20, 853-868.

727 Vandergast, A.G., Bohonak, A.J., Hathaway, S.A., Boys, J. \& Fisher, R.N. (2008) Are

728 hotspots of evolutionary potential adequately protected in southern California?

729 Biological Conservation, 141, 1648-1664.

730 Venner, S., Pélisson, P. F., Bel-Venner, M. C., Débias, F., Rajon, E. \& Menu, F. (2011).

731 Coexistence of insect species competing for a pulsed resource: Toward a unified

732 theory of biodiversity in fluctuating environments. PLoS ONE, 6, e18039

733 Yguel, B., Bailey, R., Tosh, N. D., Vialatte, A., Vasseur, C., Vitrac, X., Jean, F. \&

734 Prinzing, A. (2011) Phytophagy on phylogenetically isolated trees: why hosts

735 should escape their relatives. Ecology Letters, 14, 1117-1124.

736 SUPPORTING INFORMATION

737 Additional Supporting Information may be found in the online version of this 738 article: 
739 Appendix S1 Locality code, geographical location, host oak species and number of

740 collected individuals for each species of Curculio in California, USA.

741

\section{BIOSKETCH}

743 Raul Bonal is interested in plant-animal interactions with special emphasis on seed

744 feeding insects. He has gradually moved from local studies (just one plant and one

745 insect species) to large scale ones involving multiple species and incorporating

746 phylogenetics/population genetic analyses. He is currently investigating the

747 ecological and historical factors ruling the species assemblages of granivorous

748 insects at different spatial scales.

749

750 Author contributions: RB, JME and VLS conceived the experiment; RB, JME, AM, JO,

751 JMA and KG performed the experiments; RB, JME and JO analyzed the data; RB and

752 JME wrote the manuscript; AM, KG, and VLS provided editorial advice.

753

754 Editor: Robert Whittaker

755 


\section{$756 \quad$ Figure Legends}

757 Figure 1 Map of California with the locations of the 25 sampling sites where at 758 least 9 weevils were sampled. The proportions of each species (Curculio pardus, $C$.

759 occidentis and C. aurivestis) at each site are shown. Numbers correspond to

760 population codes described in Appendix S1.

761

762 Figure 2 DNA phylogeny of two mitochondrial (cox1 and cytb) and one nuclear

763 (EF-1a) genes for the genus Curculio. Tree topology was inferred using Maximum

764 Likelihood (GTR + I + Gamma substitution model) and Bayesian Inference. Support

765 for each node is represented by the value of Likelihood-Ratio Test for branch

766 support (above the branch) and the Bayesian probability value (below the branch).

767 Besides each weevil species is indicated the oak species in which the larvae were

768 collected, showing also if it is a red or white oak (Erythrobalanus or Leucobalanus

769 sections, red and black type, respectively). Picture of adult Curculio: author R.

770 Bonal.

771

772 Figure 3 Maps depicting the geographical genetic structure of Curculio occidentis

773 (left panel) and C. pardus (right panel) in California. Those localities with the same

774 colour were included by the SAMOVA analysis within the same group. Numbers

775 correspond to population codes described in Appendix S1.

776

777 Figure 4 Bar-plots showing the mass (left y-axis, milligrams, mean \pm SE) of (a)

778 Curculio pardus and (b) C. occidentis larvae that developed ad libitum feeding on

779 Quercus lobata acorns at different localities. The red dots within the bars

780 connected with the red line are the mean mass of the acorns exploited by each 
781 Curculio species at each locality (right y-axis, grams). Localities are arranged on 782 the x-axis in increasing order of mean acorn mass.

5

6

7

8

9

10

11

12

13

14

15

16

17

18

19

20

21

22

23

24

25

26

27

28

29

30

31

32

33

34

35

36

37

38

39

40

41

42

43

44

45

46

47

48

49

50

51

52

53

54

55

56

57

58

59

60 
Figure 1

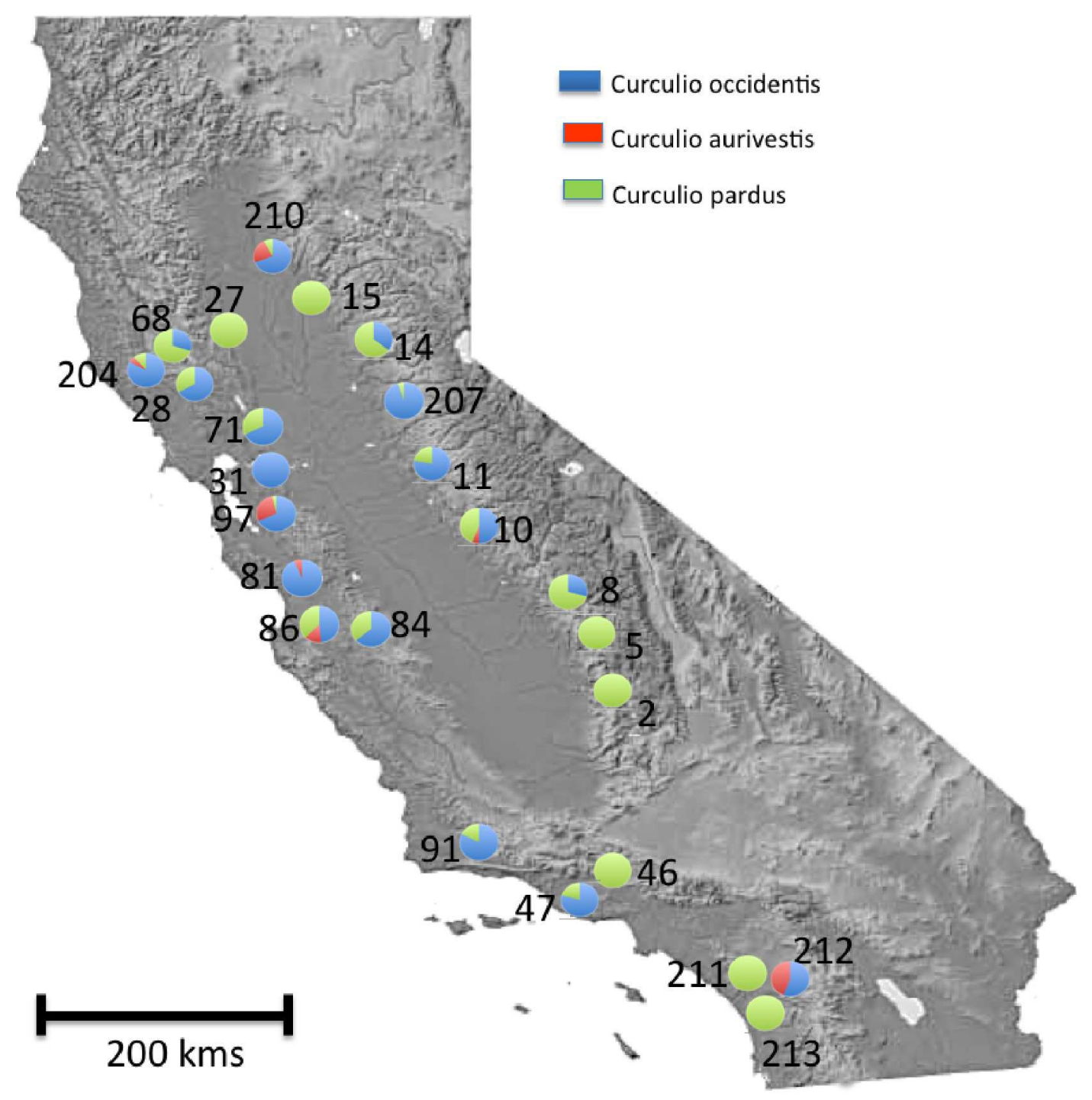


Figure 2

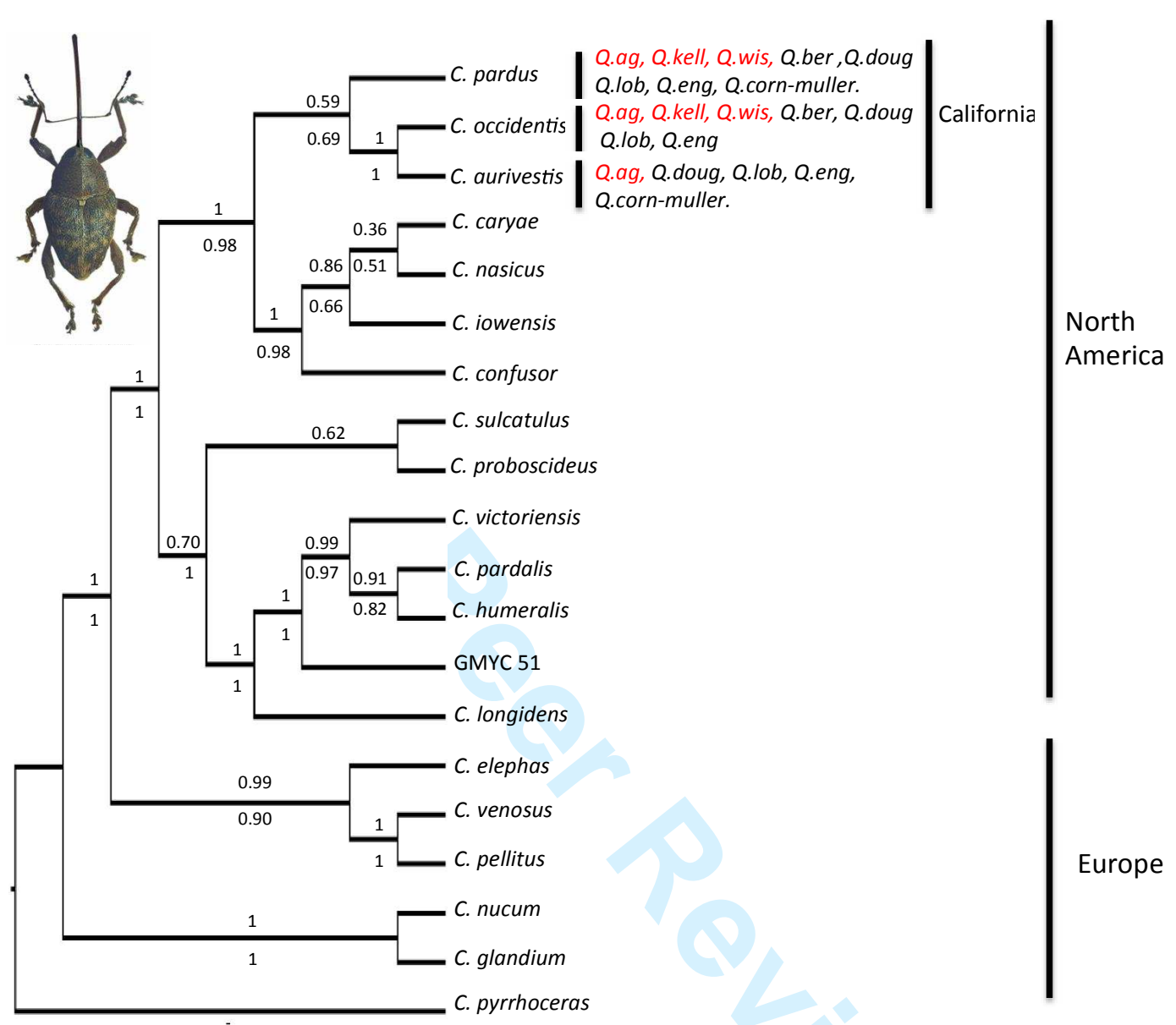


Figure 3

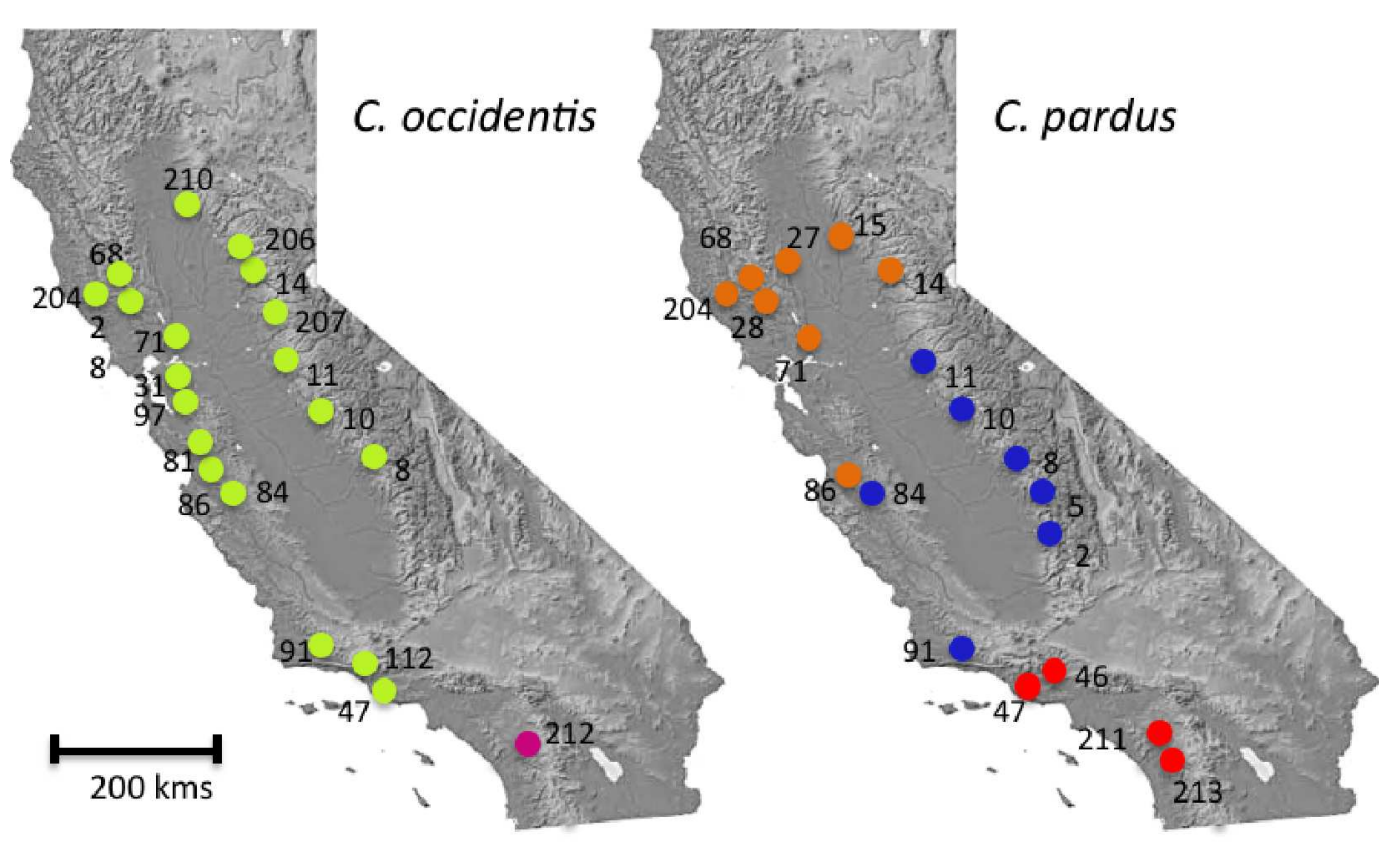

30

(31

33

34

35

36

37

38

39

40

41

42

43

44

45

46

47

48

49

50

51

52

53

54

55

56

57

58

59

60 
Figure 4
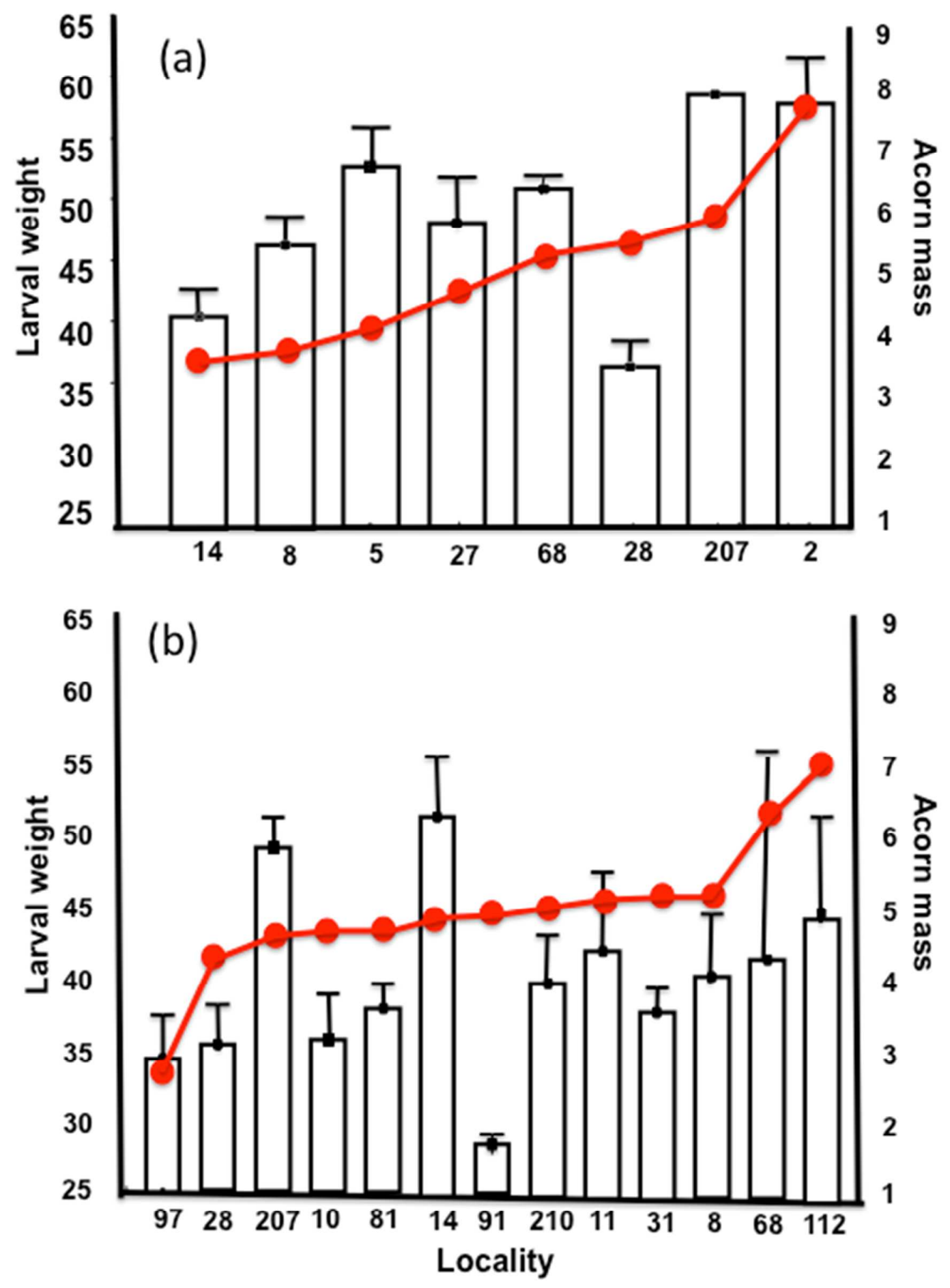


\section{SUPPORTING INFORMATION}

\section{Diversity in insect seed parasite guilds at large geographical scale: the role of host-specificity and spatial distance}

Raúl Bonal, Josep M. Espelta, Alberto Muñoz, Joaquín Ortego, José Miguel Aparicio, Keith Gaddis and Victoria L. Sork

Appendix S1 Locality code, geographical location, host oak species and number of collected individuals for each species of Curculio in California, USA.

\begin{tabular}{|c|c|c|c|c|c|c|}
\hline Locality & Latitude & Longitude & Quercus species & C. aurivestis & C. occidentis & C. pardus \\
\hline 2 & 36.060 & -119.034 & Q. lobata & 0 & 0 & 16 \\
\hline 5 & 36.476 & -119.121 & Q. lobata & 0 & 0 & 20 \\
\hline 8 & 36.725 & -119.459 & Q. lobata & 0 & 5 & 12 \\
\hline 10 & 37.462 & -119.880 & Q.lobata, Q. douglasii, Q. wislizenii & 1 & 9 & 8 \\
\hline 11 & 37.979 & -120.388 & Q. lobata, Q. kellogii & 0 & 14 & 4 \\
\hline 14 & 38.996 & -121.108 & Q. lobata, Q. kellogii, Q. wislizenii & 0 & 11 & 20 \\
\hline 15 & 39.227 & -121.422 & Q. douglasii & 0 & 0 & 16 \\
\hline 17 & 39.711 & -122.004 & Q. lobata & 0 & 2 & 0 \\
\hline 27 & 39.089 & -122.346 & Q. lobata, Q. douglasii & 0 & 0 & 19 \\
\hline 28 & 38.748 & -122.618 & $8+2$ & 0 & 10 & 5 \\
\hline 31 & 37.865 & -122.034 & 80 & 0 & 18 & 0 \\
\hline 46 & 34.412 & -118.570 & Q. lobata, Q. agrifolia & 0 & 0 & 18 \\
\hline 47 & 34.187 & -118.890 & Q. lobata, Q. agrifolia & 0 & 15 & 4 \\
\hline 68 & 39.043 & -122.775 & Q- lobata, Q. douglasii & 0 & 6 & 14 \\
\hline 71 & 38.493 & -122.148 & Q. douglasii, Q. wislizenii, Q. berberidifolia & 0 & 23 & 11 \\
\hline 81 & 36.834 & -121.552 & Q. lobata, Q. kellogii, Q. agrifolia & 2 & 31 & 0 \\
\hline 84 & 36.099 & -121.151 & Q. agrifolia & 0 & 7 & 4 \\
\hline 86 & 36.385 & -121.558 & Q. douglasii, Q. agrifolia & 4 & 14 & 11 \\
\hline 91 & 34.699 & -120.040 & Q. lobata, Q. agrifolia, Q. douglasii & 0 & 28 & 6 \\
\hline 97 & 37.354 & -121.741 & Q. lobata, Q. douglasii, Q. agrifolia & 8 & 19 & 1 \\
\hline 112 & 34.455 & -119.230 & Q. lobata, Q. agrifolia & 0 & 4 & 2 \\
\hline 204 & 38.985 & -122.970 & Q. douglasii, Q. berberidifolia & 2 & 29 & 4 \\
\hline 206 & 39.210 & -121.300 & Q. lobata & 0 & 7 & 0 \\
\hline 207 & 38.486 & -120.846 & Q. lobata & 0 & 18 & 1 \\
\hline 210 & 39.636 & -121.946 & Q. lobata & 3 & 9 & 1 \\
\hline 211 & 33.272 & -117.183 & Q. berberidifolia, Q. engelmanii & 0 & 0 & 10 \\
\hline 212 & 33.275 & -116.623 & Q. agrifolia, Q. engelmanii, Q. cornell.-mulleri & 4 & 5 & 0 \\
\hline 213 & 33.235 & -117.022 & Q. berberidifolia, Q. engelmanii & 0 & 0 & 10 \\
\hline 214 & 33.065 & -116.401 & Q. engelmanii, Q. cornellius mullerii & 1 & 0 & 2 \\
\hline 215 & 33.042 & -116.325 & Q. engelmanii & 0 & 1 & 0 \\
\hline
\end{tabular}

